\title{
Comparing Perceived Social Support and Perceived Stress in Women with and without Polycystic Ovary Syndrome Refereed to Fatemiyeh Hospital in Hamadan City
}

\section{Fatemeh Shobeiri (PhD) ${ }^{1}$, Maryam Ataollahi (MSc) ${ }^{2, *}$, Safoura Jahanara (MSc) ${ }^{3}$, Ghodratollah Roshanaei (PhD) ${ }^{4}$}

${ }^{1}$ Associate Professor Maternal \& Child Health Research Center for Child and Maternity Care, Hamadan University of Medical Sciences, Hamadan, Iran

2 Fatemiyeh Hospital, Hamadan University of Medical Sciences, Hamadan, Iran

${ }^{3}$ School of Nursing and Midwifery, Hamadan University of Medical Sciences, Hamadan, Iran

${ }^{4}$ Associated Professor, Department of Biostatistics, Diseases Research Center, School of Public Health, Hamadan University of Medical Sciences, Hamadan, Iran

* Corresponding Author: Maryam Ataollahi, Fatemiyeh Hospital, Hamadan University of Medical Sciences, Hamadan, Iran.Tel: 08138380319; Email: maryam.ataollahi@ymail.com

Received: $23 / 09 / 2017$

Accepted: 22/02/2018

\section{How to Cite this Article:}

Shobeiri F, Ataollahi M, Jahanara

S, Roshanaei G. Comparing perceived Social Support and Perceived Stress in Women with and without Polycystic Ovary Syndrome refereed to Fatemiyeh Hospital in Hamadan City. Pajouhan Scientific Journal. 2018; 16(4): 46-52. DOI: 10.29252/psj.16.4.46

\section{Abstract}

Background and Objectives: Polycystic Ovary Syndrome is a common issue that affects womens in pregnant age and international statistics indicate that this syndrome is increasing. The aim of this study was to compare perceived social support and perceived stress in women with and without Polycystic Ovary Syndrome refereed to Fatemiyeh Hospital in Hamadan city, Iran, 2016.

Materials and Methods: This descriptive-comparative study was carried out with convenience sampling on 116 women with Polycystic Ovary Syndrome and 116 women without it refereed to Fatemiyeh Hospital in Hamadan city. All data were collected using demographic questionnaire, perceived social support and perceived stress questionnaires, Polycystic Ovary Syndrome questionnaire and analyzed using descriptive statistics, Mann-Whitney tests, independent T-test, and chi-square in SPSS v.17. Results: Results showed that there were no significant difference between two groups in terms of demographic charactersitics including age, weight, BMI, education level and there was statistically significant difference between the two groups in terms of perceived social support and perceived stress questionnaires $(p<0.05)$.

Conclusions: Given the results, training and awareness are necessary for women and emphasis on perceived social support and perceived stress are recommended as a non-medical option for prevention of Polycystic Ovary Syndrome.

Keywords: Perceived social support; Perceived stress; Polycystic Ovary Syndrome 


\title{
مقايسه استرس و حمايت اجتماعى درك شده در زنان مبتلا و غيرمبتلا به سندرم تخملان بلى كيستيك مراجعه كننده به مر كز آموزشى درمانى فاطميه شهر همدان
}

\author{
فاطمه شبيرى'، مريم عطاللهيى r."، صفورا جهمان آراب، قدرت الله روشنايى
} ' استادكروه مامايى، مركز تحقيقات مادر و كودك، دانشكده يرستارى و مامايى، دانشعاه علوم يزشكى همدان، همدان، ايران

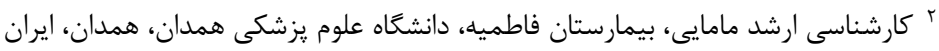

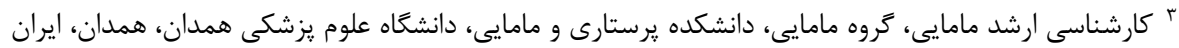

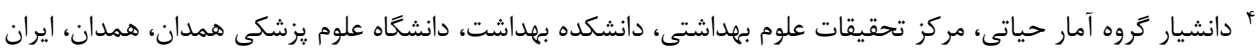

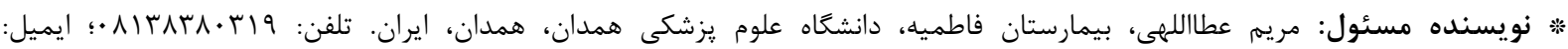
maryam.ataollahi@ymail.com

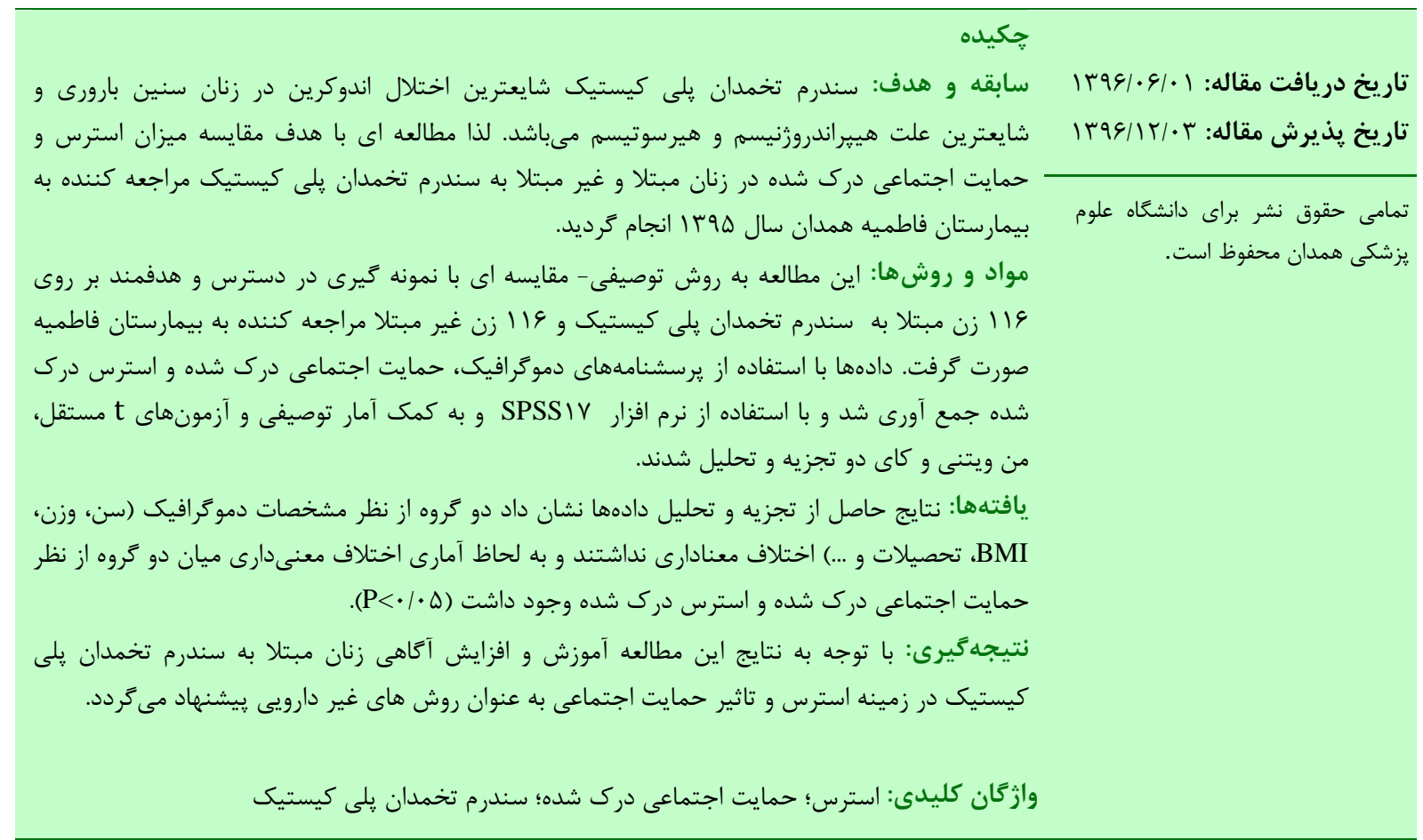

(افسردگى، استرس و اضطراب) مى باشند [Y-Y]]. هيرسوتيسه،

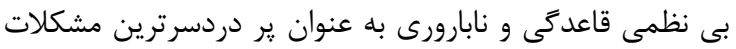

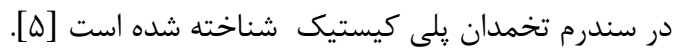

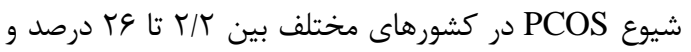

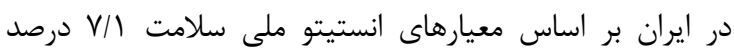

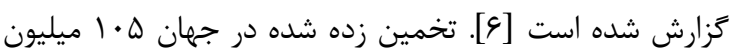

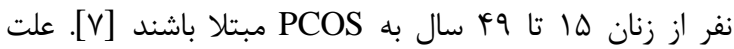

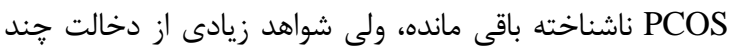
زن كه در شرايط مناسب محيطى، خصوصا فاكتورهاى تغذيه ائ،

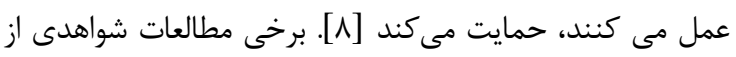

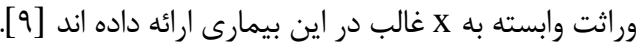

سندرم تخمدان يلى كيستيك شايعترين اختلال اندوكرين

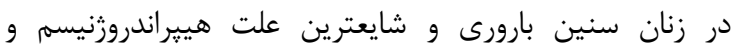

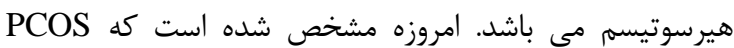

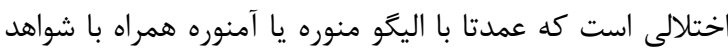

بالينى يا آزمايشخاهى هيبراندروزنمى مشخص مى آىردد [1]

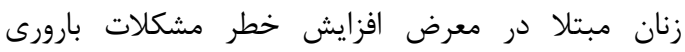

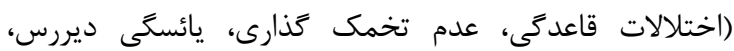

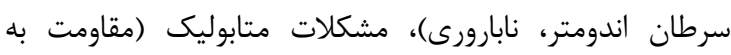

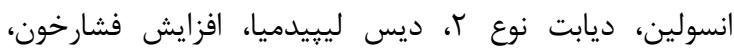
بيمارىهاى قلبى-عروقى)، مشكلات جسمى (جاقى مركزى، دئ،

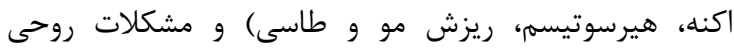




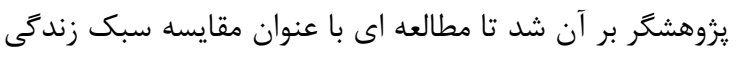

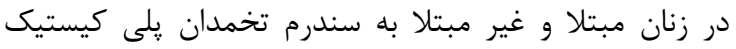

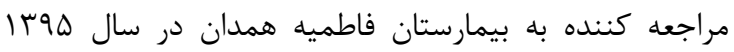
انجام دهد.

\section{مواد و روشها}

اين مطالعه به روش توصيفى- تحليلى مىباشد. نمونه گيرى به صورت نمونه گيرى در دسترس و هدفمند از ميان

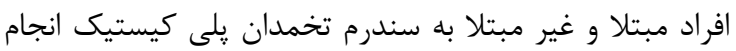

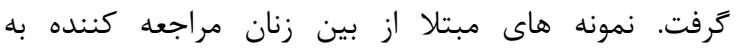

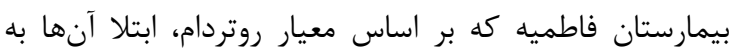

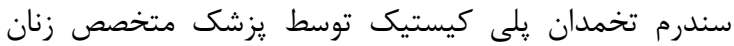
قطعى شده بود، انتخاب شدند.

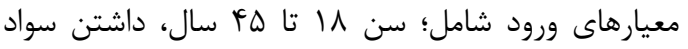

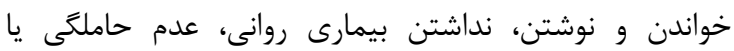
شيردهى، فاقد بيمارىهاى شناخته شده طبى به اظهار فرد يا بـ برى

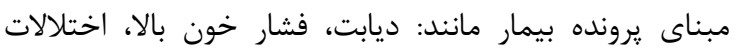
تيروييدى، هيير يرولاكتينمى، سندرم كوشينگ، هييريلازى غداد

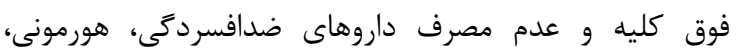

جلو گيرى از باردارى، كلوكورتيكوييدها و ضد جاقى بودند.

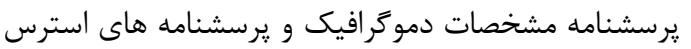

درى شده و حمايت اجتماعى درى شده از طريق مصاحبه

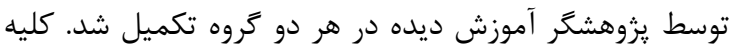

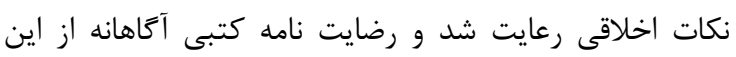
افراد كسب كرديد. براى تعيين تعداد نمونه با استفاده از رابطه زير:

$n=\frac{\left(Z_{1-\frac{\alpha}{2}}+Z_{1-\beta}\right)^{2}\left(\sigma_{1}^{2}+\sigma_{2}^{2}\right)}{\left(\mu_{2}-\mu_{1}\right)^{2}}$

كه در آن شد. با در نظر كرفتن خطاى نوع اول ه درصد و توان آزمون

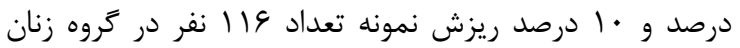

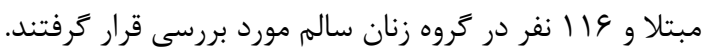

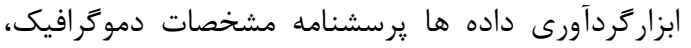

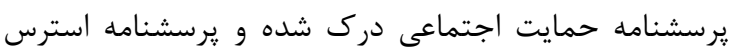
درى شده بود . يرسشنامه حمايت اجتماعى درك شده شهاه Zimet

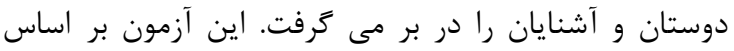

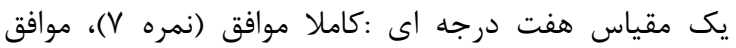

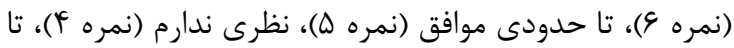

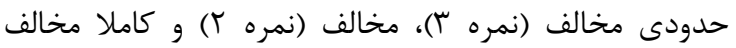
(نمرها) ساخته شد. حداقل و حداكثر امتياز كسب شده دره
Jedel

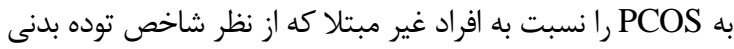

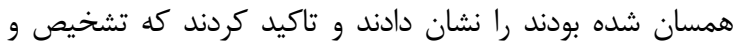

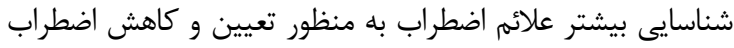

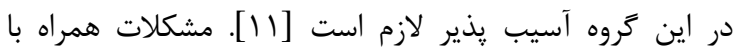

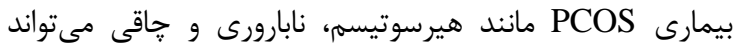

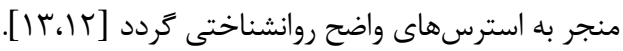

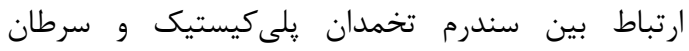

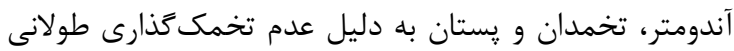

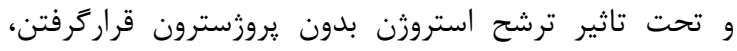

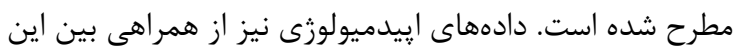

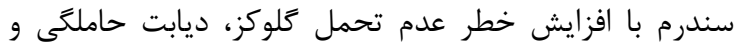

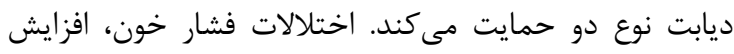
كلسترول، ترى كليسيريد و سندرم متابوليك در اين افراد شايع دائ

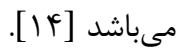
از آنجا كه مطالعات انجام شده نشان دهنده در معرض خطر

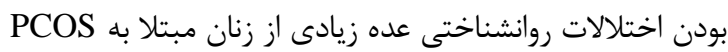

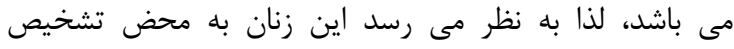

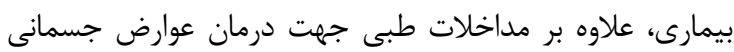
اين سندرم، نياز به غربالكرى اختلالات روانشناختى نيز دارئ دارند.

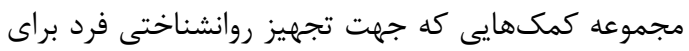

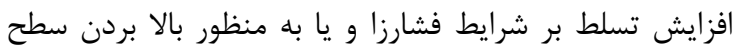

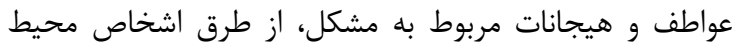

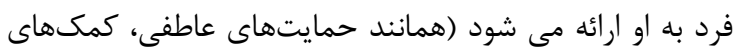

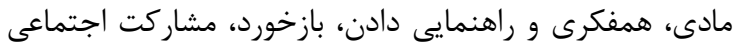

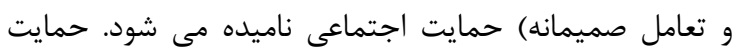

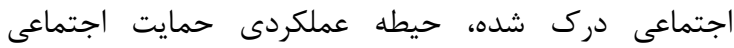

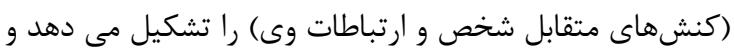

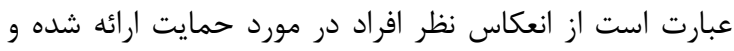
احساس دسترسى به حمايت در صورت نياز، حمايت اجتماعى إنى

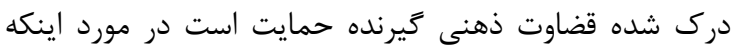

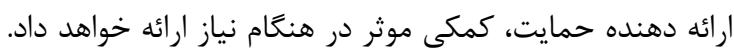

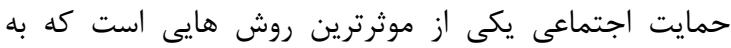

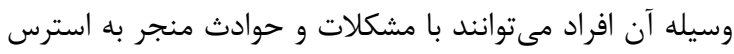

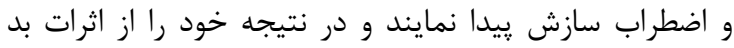

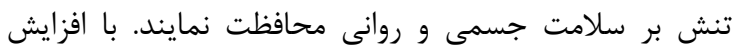

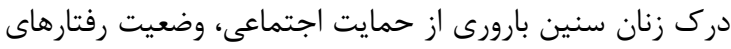

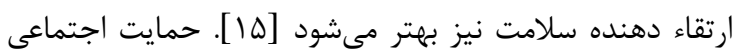
همجون سيرى مانع از نفوذ استرس در فرد مى

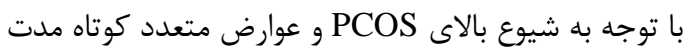
و بلند مدت آن و عدم شناسايى علت و درمان قطعى اين بالن

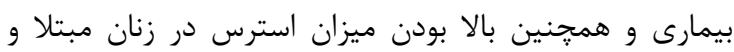

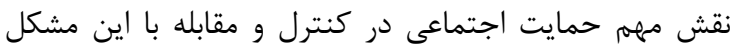


آمده است [Tr]. جهت كنترل عوامل مخدوش كننده Y گروه

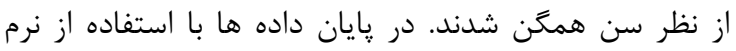

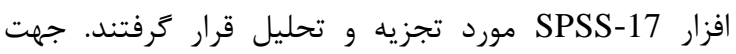

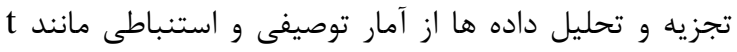

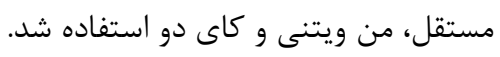

\section{بافته.}

نتايج مطالعه نشان داد كه ميانگَين سنى در كروه زنان

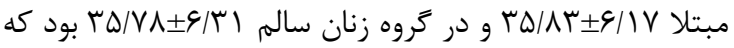

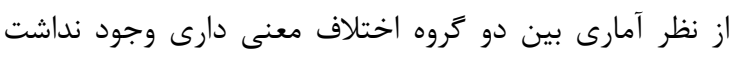

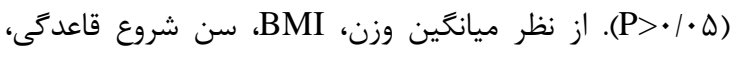

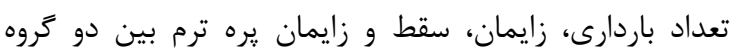

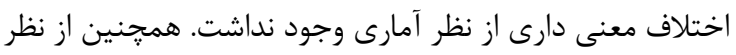

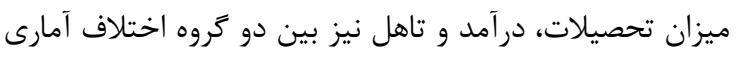

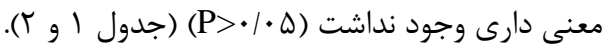

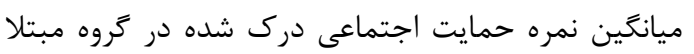
به سندرم تخمدان يلى كيستيك زنان سالم

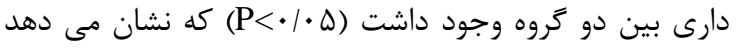

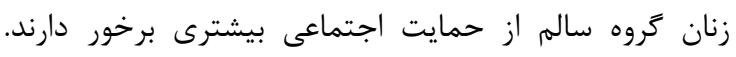

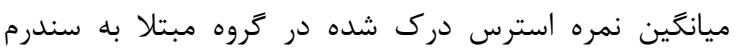
تخمدان يلى كيستيك

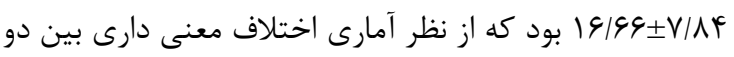

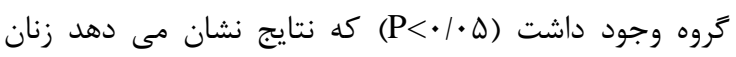

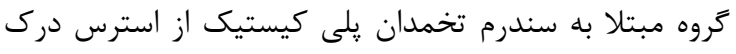
شده بالاترى برخور دارند (جدول مبن).

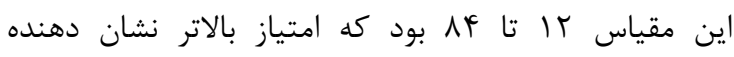

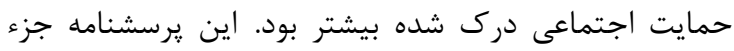

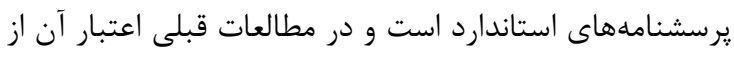
روش اعتبار همزمان سازه و اعتبار ييش بينى تاييد كرديده است [IV]

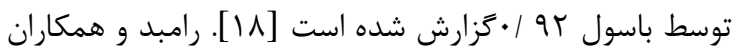

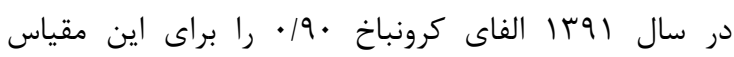
محاسبه كردند [19]

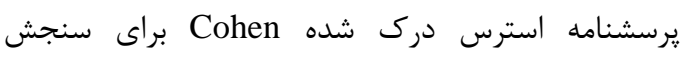
استرس عمومى درك شده در يك ماه گذشته به كار مى رود.

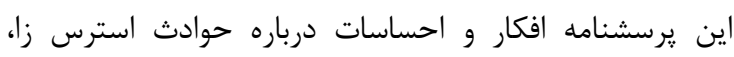

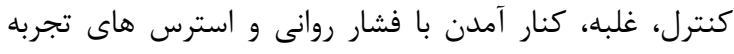

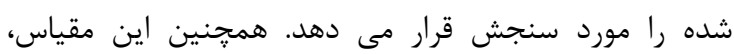

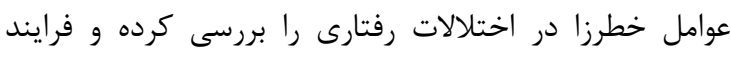

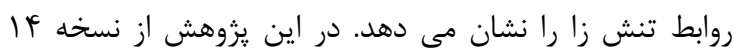

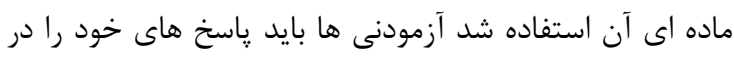

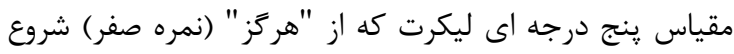

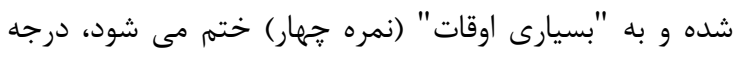
بندى مى كردند. نمره كلى استرس درك شده به به سه سه سطح تقسيم كرديد. كمترين امتياز كسب شده صفر و و بيشترين

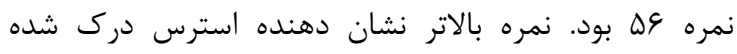

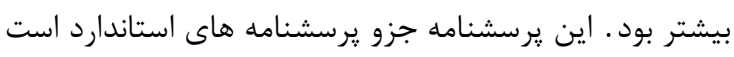

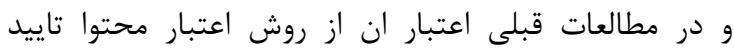

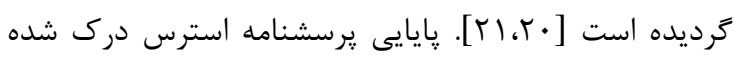

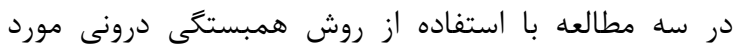

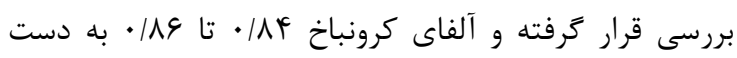

جدول ا: مقايسه مشخصات دموكرافيك در دو گروه مبتلا و غيرمبتلا به سندرم تخمدان يلى كيستيك افي

\begin{tabular}{|c|c|c|c|}
\hline P-value & 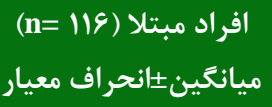 & انحراف معيار ذميانتين & متغير ها \\
\hline.$/ 990$ & $r \Delta / \wedge r \pm \varphi / / V$ & $r \Delta / V \Lambda \pm g / \Gamma)$ & سن (سال) \\
\hline$\cdot / T / \Delta$ & $\varepsilon N / F \cdot \pm V / \cdot V$ & $99 / 99 \pm V / 9 V$ & وزن (كيلو گرم) \\
\hline 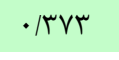 & $r E / F T \pm Y / 9 \Delta$ & $r \Delta / 91 \pm r / 1 r$ & BMI (كيلو گرم/متر مربع) \\
\hline - DTS & $\mid r / \Delta \Delta \pm r / r \varepsilon$ & $1 r / 9 \Delta \pm 1 / 1 r$ & سن شروع قاعدگى (سال) \\
\hline
\end{tabular}

جدول ب: توزيع فراوانى مشخصات دموكرافيك در دو گروه مبتلا و غيرمبتلا به سندرم تخمدان يلى كيستيك

\begin{tabular}{|c|c|c|c|c|c|}
\hline \multirow{2}{*}{ P-value } & \multicolumn{2}{|c|}{ افراد مبتلا (1)=|9) } & \multicolumn{2}{|c|}{ افراد سالم (1)=|(n) } & \multirow{2}{*}{ متغير ها } \\
\hline & درصد & فراوانى & درصد & فراوانى & \\
\hline \multirow{3}{*}{$\cdot / V \cdot 9$} & & & & & تحصيلات \\
\hline & $9 \Delta / \Delta$ & Ve & $94 / 90$ & Ar & دييلم و بالاتر \\
\hline & $r F / D$ & f. & $r \Delta / r \Delta$ & my & كمتر از ديِلهم \\
\hline \multirow{3}{*}{. /AT. } & & & & & تعداد باردارى \\
\hline & $\Lambda \cdot / 1 \mathrm{~V}$ & $9 \pi$ & $V F / I T$ & $\wedge \varphi$ & $\cdot-r$ \\
\hline & 19/14 & זr & $r \Delta / \wedge V$ & r. & بيشتر از r \\
\hline
\end{tabular}




\begin{tabular}{|c|c|c|c|c|c|}
\hline & & & & & ادامه جدول r. \\
\hline \multirow[t]{2}{*}{$\cdot / 949$} & $\Lambda \Delta / \mu F$ & 99 & VQ/TI & 95 & r-عداد زايمان \\
\hline & $\mid f / 94$ & IV & $r \cdot 199$ & TF & بيشتر از ب \\
\hline \multirow{3}{*}{$\cdot 19 \Delta 8$} & & & & & سقط \\
\hline & $94 / 1$ & $1 \cdot 1$ & $9 \vee / 41$ & 111 & $\cdot-1$ \\
\hline & $9 / 9$ & $\wedge$ & $r / \Delta 9$ & r & بيشتر از 1 \\
\hline \multirow[t]{2}{*}{ •/ / १९ } & $9 \vee / 41$ & $11 \pi$ & qr/Ar & 11. & 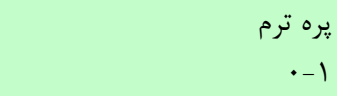 \\
\hline & $r / \Delta 9$ & r & $\Delta / 1 \Lambda$ & 4 & بيشتر از 1 \\
\hline \multirow{3}{*}{$\cdot 1199$} & & & & & درآ آمد ماهانه (تومان) \\
\hline & TN/A & q. & $r 1 / 9$ & VF & كمتر از يك ميليون \\
\hline & $91 / 4$ & rq & $9 N / 1$ & ft & مساوى و بيشتر از يك ميليون \\
\hline \multirow[t]{2}{*}{ r } & 11 & 94 & $V F / I$ & $\wedge \varepsilon$ & وضاهل \\
\hline & 19 & Tr & $r Q / q$ & r. & مجرد \\
\hline
\end{tabular}

جدول ب: مقايسه ميانكين نمره حمايت اجتماعى و استرس درك شده در دو كروه مبتلا و غير مبتلا به سندرم تخمدان يلى كيستيك

\begin{tabular}{|c|c|c|c|}
\hline P-value & 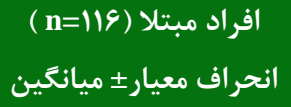 & 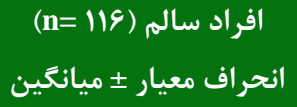 & متغير ها \\
\hline$\cdot 1 \cdot \cdot 1$ & $F \Delta / \wedge \Lambda \pm \mid F / \varphi$ & $\Delta V / \& V \pm q / r)$ & حمايت اجتماعى درى شده \\
\hline$\cdot 1 \cdot \cdot 1$ & $T V / F I \pm E / F V$ & 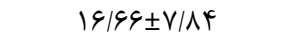 & استرس درى شده \\
\hline
\end{tabular}

مشكلات جنسى در زنان مبتلا به PCOS بالاتر است [YN]. همجنين Hollinrake و همكاران نيز معتقدان متاند كه خطان

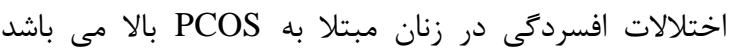

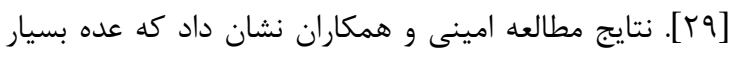
زيادى از اين بيماران در معرض خطر مشكلات روانشناختى بوده

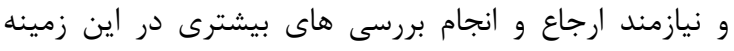

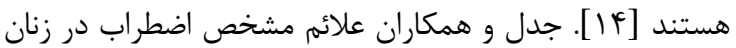

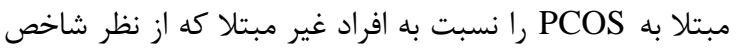

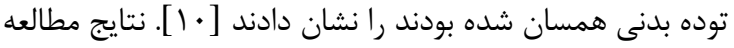

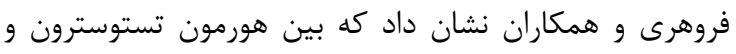
حيطه عاطفى كيفيت زندگى اين زنان ارتباط معكوس و دار معنى

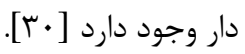
از آنجا كه مطالعات انجام شده نشان دهنداند إندان درمعرض

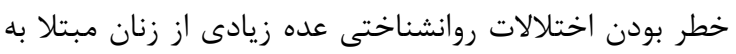
مCOS

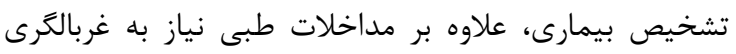

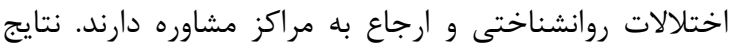

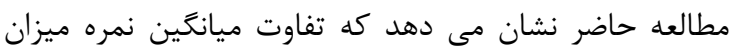

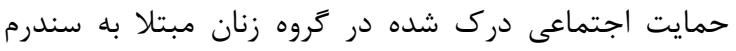

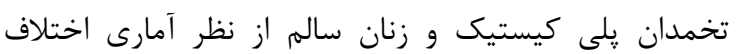

با وجود ييشرفت جشمخير تكنولوزى در دنياى امروزى و

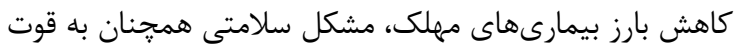

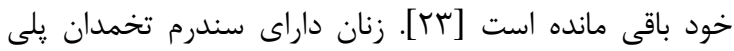

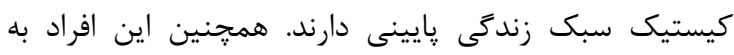

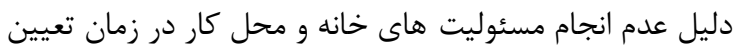

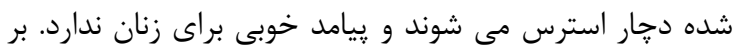

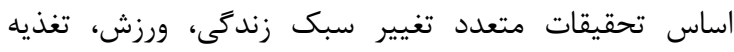

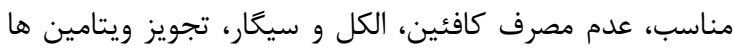

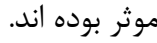

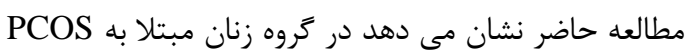

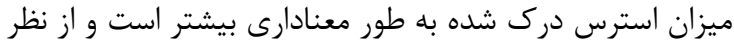

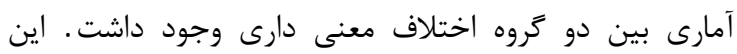

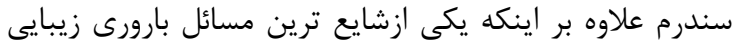

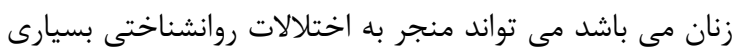

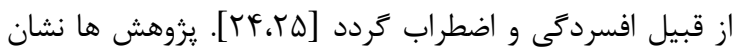

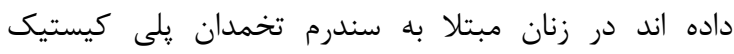

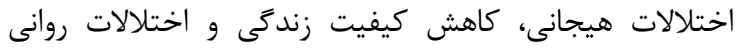

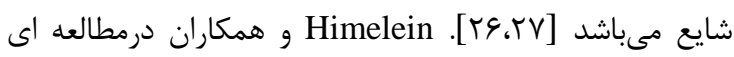

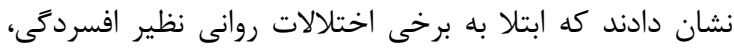

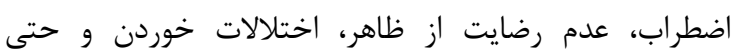




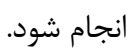

\section{نتيجه كيرى}

در مجموع بيمارى سندرم تخمدان يلى كيستيك با

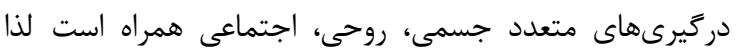

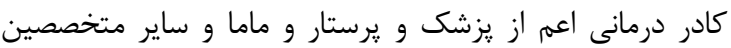

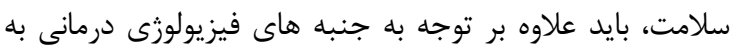

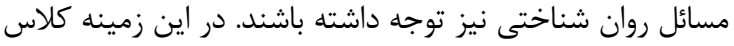

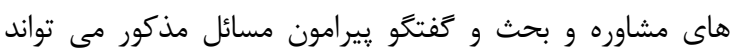

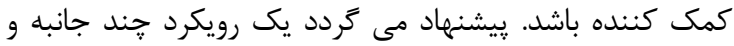

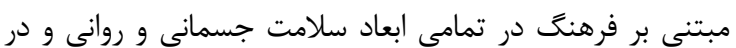
نهايت كاربرد درمان هاى مناسب براى اين افراد انجام شود.

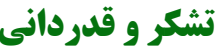

اين مطالعه حاصل طرح مصوب معاونت يزوهشى دانشعاه

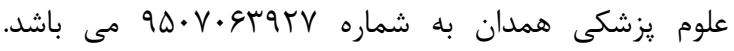
يزوهشخران از مسئولين محترم و اعضاى كميته مركز تحقيقات مراقبت هاى مادر وكودى، شوراى يزوهشى دانشكاه علوم يزشكى همدان، رياست و كاركنان بيمارستان فاطميه و بانوان شركت كننده در اين يزوهش نمايت رياست تشكر و امتنان را دارند.

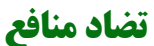
اين مطالعه براى نويسندگًان هيج گونه تضاد منافعى نداشته

\section{REFERENCES}

1. Novak E, Berek J, Hillard P, Adashi E. Novak's gynecology. 13th ed. London: Lippincott Williams and Wilkins; 2012. p,1075-1090.

2. Bozdag G, Yildiz B. Interventions for the metabolic dysfunction in polycystic ovary syndrome. Steroids. 2013;78(8): 777-81.

3. Balakrishnan SH. Adolescent Polycystic Ovary Syndrome. Health Science. 2013;2(1):JS004B.

4. Lass N, Kleber M, Winkel K, Wunsch R, Reinehr TH. Effect of Lifestyle Intervention on Features of Polycystic Ovarian Syndrome, Metabolic Syndrome and Intima-Media Thickness in Obese Adolescent Girls. J Clin Endocrinol Metab, November.2011;96(11):3533-3540.

5. Allahbadia N, Merchant R. Polycystic ovary syndrome and impact on health. Middle East Fertility Society Journal. 2011;16:19-37.

6. Ramezani Tehrani F, Simbar M, Tohidi M, Hosseinpanah F, Azizi F. The prevalence of poly cystic ovary syndrome in a community sample of Iranian population: Iranian PCOS prevalence study. Reproductive Biology and Endocrinology. 2011; 9:39. doi: 10.1186/1477-7827-9-39.

7. Nasiri Amiri F, Ramezani Tehrani F, Simbar M, Mohammadpour Thamtan R. Concerns of Women with Polycystic Ovary Syndrome: AQualitative Study. Iranian Journal of Endocrinology and Metabolism. 2013;15(1): pp.41-51. (Persian)

8. Tomic V, Tomic J. Inferility Treatment in Patients with Polycystic Ovary Syndrome (PCOS). J Fertiliz In Vitro. 2012; 2:e113. doi:10.4172/2165-7491.1000e113

9. Badawy A, Elnashar A. Treatment options for polycystic
معنى دارى داشت كه نشان مى دهد گروه زنان سالم حمايت اجتماعى بيشترى را درك مى كنـن.

مجموعه كمك هايى كه جهت تجهيز روانشناختى فرد براى افزايش تسلط بر شرايط فشارزا و يا به منظور بالا بردن سطح عواطف و هيجانات مربوط به مشكل، از طرق اشخاص محيط فرد به او ارائه مى شود (همانند حمايت هاى عاطفى، كمك هاى مادى، همفكرى و راهنمايى دادن، بازخورد، مشاركت اجتماعى و تعامل صميمانه) حمايت اجتماعى ناميده

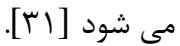

مطالعات نشان داده اند كه بيماران حمايت هاى مختلفى ران در طى ساز گارى با بيمارى دريافت مى كنـند كه بيشترين حمايت را از طرف خانواده دريافت نموده اند. حمايت خانواده به عنوان يكى از مهمترين منابع مورد نياز بر آرامش و سازگًارى است [Tr]]. در واقع حمايت و پشتيبانى توسط همسر مهمترين منبع حمايتى افراد در دوره هاى بيمارى است [سب]. يافته هاى مطالعات ديخر تاثير مثبت همتايان در مواجهه بهتر با بيمارى را

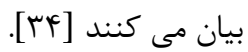
با توجه به نتايج مطالعه حاضر كه ميزان حمايت اجتماعى درك شده در زنان مبتلا به سندرم تخمدان يلى كيستبك از زنان سالم كمتر بود و با توجه به نقش مهرم حمايت اجتماعى در سازگًاى بيشتر بيماران توصيه مى شود حمايت خانواده و اطرافيان بيمار افزايش يابد و در اين زمينه جامعه، خانواده، دوستان و اطرافيان بيمار آَاهى ييدا كنند و در جهت ترويج افزايش حمايت هاى اجتماعى مطالعات و اقدامات بيشترى

ovary syndrome. International Journal of Women's Health. 2011;3: 25-35.

10. Jedel E, Waern M, Gustafson D, Landen M, Eriksson E, Holm G, Nilsson L, Lind A, Janson P.O , Stener Victorin E. Anxiety and depression symptoms in women with polycystic ovary syndrome compared with controls matched for body mass index. Human Reproduction. 2010;25(2 ): 450-456.

11. Kerchner A, Lester W, Stuart SP, Dokras A. Risk of depression and other mental health disorders in women with polycystic ovary syndrome: a longitudinal studyFertil Steril. 2009;91: 207-212.

12. Ghoreishi A, Rahmanpour H, Mousavinasab N. Evaluation of Psychological Problems in Teenagers Suffering from Polycystic Ovary Syndrome.Journal of Zanjan University of Medical Sciences.2011;18(73):76-83.(Persian)

13. Arshad M, Moradi S, Ahmmadkhani A, Emami Z. Increased Prevalence of Depression in Women with Polycystic Ovary Syndrome. Iranian Journal of Endocrinology and Metabolism. 2012;13(6): 582-586. (Persian)

14. Amini L, Ghorbani B, Seyedfatemi N. Mental Health of Women with Polycystic Ovary Syndrome (PCOS) and some of its Socio-demographic Determinants. Iran Journal of Nursing (IJN). 2012;25(78): 34-41. (Persian)

15. kim HS, Sherman DK, Taylor SE. Culture and social support. American Psychologist. 2008;63(6): 518-526.

16. Khalili F, Sam SH, Sharifirad GH, Hassanzadeh A, Kazemi M. The Relationship between Perceived Social Support and Social Health of Elderly. Health System Research. 2011;7(6): 1216-1225. (Persian) 
17. Başol G. Validity and reliability of the Multidimensional scale of perceived social support-revised, with a Turkish sample. Social Behavior and Personality: 38- Strazdins L, Broom D. The mental health costs and benefits of giving social support. International Journal of StressManagement. 2008;36(10):1303-13.

18. Zimet GD, Dahlem NW, Zimet SG, Farley GK. The multidimensional scale of perceived social support. Journal of personality assessment. 1988;52(1):30-41.

19. Rambod M, Rafii F. Perceived social support and quality of life in Iranian hemodialysis patients. Journal of Nursing Scholarship. 2010;42(3):242-9.

20. Hazavehei MM, Moghimbeigi A, Hamidi Y. Assessing stress level and stress management among Hamadan hospital nurses based on precede model. The Horizon of Medical Sciences. 2012;18(2):78-85.

21. Azimi A, Asgari M, Payami M, Kashafi M . The Effect of Progressive Muscle Relaxation on Perceived Stress of Patients with Myocardial Infarction. ZUMS Journal.2012 ;20 (81):18-27. (Persian)

22. Cohen S, Kamarck T, Mermelstein R. A global measure of perceived stress. Journal of health and social behavior. 1983:385-96.

23. Nikniaz A. Hygiene aim of Development, Abstract papers Of Hygiene increasing congress ,Health center of Number one .TABRIZ, 2002: 1. (Persian)

24. Sundararaman PG, Shweta, Sridhar GR. Psychosocial aspects of women with polycystic ovary syndrome from south India. J Assoc Physicians India. 2008;56:945-8.

25. Benson S, Hahn S, Tan S, Janssen OE, Schedlowski M, Elsenbruch S. Maladaptive coping with illness in women with polycystic ovary syndrome. J ObstetGynecol Neonatal Nurs. 2010;39(1):37-45.
26. Arshad M, Moradi S, Ahmmadkhani A, Emami Z.nIncreased Prevalence of Depression in Women with Polycystic Ovary Syndrome. Iranian Journal of Endocrinology and Metabolism. 2012;13(6):582-586. (Persian)

27. Kumarapeli V, SeneviratneRde A, Wijeyaratne C. Healthrelated quality of life and psychological distress in polycystic ovary syndrome: a hidden facet in South Asian women. BJOG. 2011;118(3):319-28.

28. Himelein MJ, Thatcher SS. Polycystic ovary syndrome and mental health: A review. ObstetGynecolSurv. 2006; 61(11):723-32.

29. Hollinrake E, Abreu A, Maifeld M, Van Voorhis BJ, Dokras A. Increased risk of depressive disorders in women with polycystic ovary syndrome. FertilSteril. 2007;87(6):1369-76.

30. Forohari S, Heidari JH, Tavana Z, Mihanpor H, Sayadi M, Shayan A, Youshani N. Effect of some hormones related to polycystic ovary syndrome on health-related quality of life. IJOGI. 2016;186(18):17-27.

31. Chan CW, Hon HC, Chien WT, Lopez V.Social support and coping in Chinese patients undergoing cancer surgery. Cancer Nursing. 2004;27(3): 230-236.

32. Bazarganipour F, Hosseini N, Taghavi SA. Coping Strategies in Patients with Polycystic Ovarian Syndrome; A Qualitative Research. Journal of Knowledge \& Health Shahroud University of Medical Sciences 2014; 9 (3):28-39. (Persian)

33. Zamanzadeh V, Heidarzadeh M, OshvandiKh, Lakdizaji S. Relationship between quality of life and social support in hemodialysis patients. J of Tabriz Univ of Med Sci 2007;29(1):49-54. (Persian)

34. Jouybari L, Oskouie SF, Ahmadi F. Hospitalized patients: a missed concept. Bimonthly Iran J of Nurs. 2006;19(47): 90101. (Persian) 